\title{
Making an implant level cast with the angled abutment and acrylic resin cap : A clinical report
}

\author{
Hamid Neshandar Asli ${ }^{1}$ and Bardia Vadiati Saberi \\ ${ }^{1}$ Associate Professor, Dental Sciences Research Center, Department of Prosthodontics, Faculty of Dentistry, \\ Guilan University of Medical Sciences, Rasht, Iran \\ ${ }^{2}$ Assistant Professor, Dental Sciences Research Center, Department of periodontology, Faculty of dentistry, \\ Guilan University of Medical sciences, Rasht, Iran
}

\begin{abstract}
Accurate casting to achieve a passive prosthesis is very important. Also, fabrication of a restoration because of the proximity implants remains a challenge. In this case report, one approach to this problem is discussed. Also, the goal of this study is analyzing fabrication an implant level cast with the help of angled abutment and acrylic resin cap. The advantage of the mentioned method is that first putting abutments provide the possibility of casting from a transferable component. Second, increase accuracy of casting by correction of path of improper implants through angled abutment.
\end{abstract}

\section{KEY WORDS: IMPLANT LEVEL CAST, ANGLED ABUTMENT, ACRYLIC RESIN}

\section{INTRODUCTION}

Preferably, installation of implant fixtures are important in that should be parallel to each other and to adjacent teeth and be aligned vertically with axial forces. But, when fixtures are improperly positioned and soft-tissue defects are visible, conventional abutments cannot be used; therefore the use of custom angled abutments is helpful (Gualini and Berglundh, 2003). However, there is controversy about using of angled abutment. Because, some studies recommend that angled abutments result in increased stress on supporting implants, adjacent bone, and the prosthesis (Lin et al. 2008). Also, there is a challenge in fabrication of restoration on implants which have proximity together (Chaimattayompol et al. 2003, Baig et al. 2014; Papaspyridakos et al. 2015).

Proximity of implant scan cause problems, however there are a number of methods to facilitate these problems (Assif et al. 1996; Selecman et al. 2009). One of the methods is using altered metal impression coping. But, sometimes this shape change is not possible because severe proximity of the implants (Chaimattayompol

\section{ARTICLE INFORMATION:}

*Corresponding Author: dr.bardia_vad@yahoo.com Received $1^{\text {st }}$ March, 2017

Accepted after revision $19^{\text {th }}$ June, 2017

BBRC Print ISSN: 0974-6455

Online ISSN: 2321-4007 CODEN: USA BBRCBA

$\therefore$ Thomson Reuters ISI ESC and Crossref Indexed Journal

. NAAS Journal Score 2017: 4.31 Cosmos IF : 4.006

$\odot$ A Society of Science and Nature Publication, 2017. All rights reserved.

Online Contents Available at: http//www.bbrc.in/ 


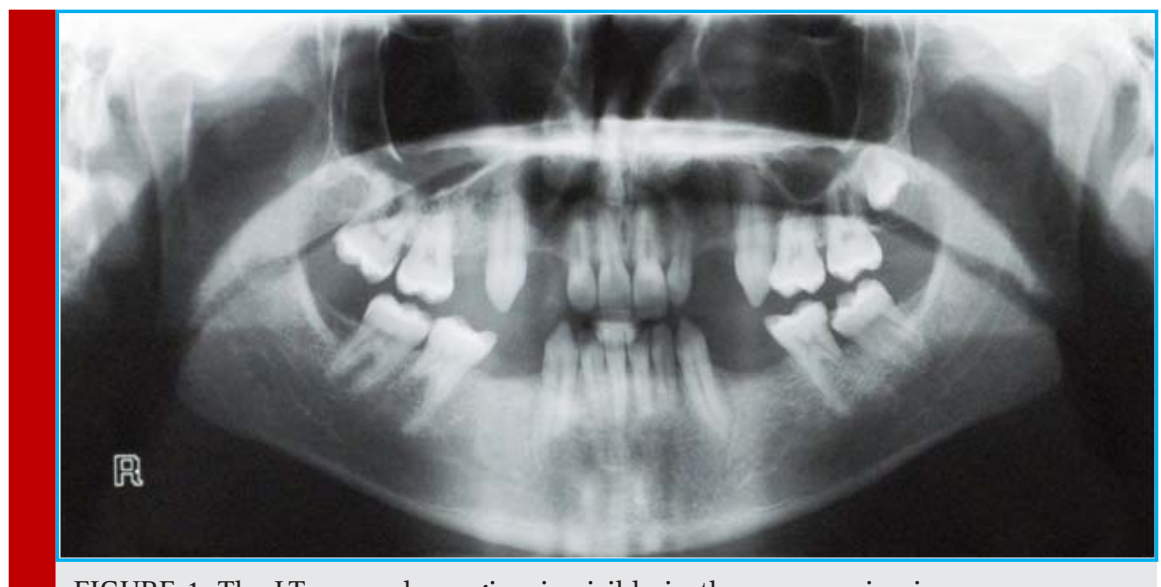

FIGURE 1. The LT. premolar region is visible in the panoramic view.

et al. 2003). Another method is using of plastic impression copings to make implant level casts (Choi et al. 2006) but not all implant systems do not have this feature. Also, deformation of these plastic impression copings can affect the accuracy and strength, and reduce involvement them in impression. This case report reviews other method to make an implant level cast by an angled abutment and acrylic resin cap.

\section{MATERIAL AND METHODS}

Case presentation. Patient F.Z, aged 35 years with a noncontributory medical history, came to the dental office with two implant fixtures in region of LT. Mandibular premolar teeth (teeth \# 20, 21). At clinical and radiographic examination, we found significant proximity between them (Fig. 1, 2). Also, Radiographic and clinical examination suggested that osseous integration and healing were within normal limits.

Clinical \& laboratory procedures. Design and fabrication method of the fixed prosthesis determine the impression technique, especially when implants are 2 or more (Kupeyan et al. 1995). The first, each of SICmax implants Ø $3.7 \mathrm{~mm} / 9.5 \mathrm{~mm}$ (SIC invent AG) with a stock try and use of C-Silicone Impression Material putty and Light Body Wash (speedex-Coltene/Whaledent) were under the impression. After the impression, gingival mask to reconstruct soft tissue height and gingival reproduction (Gingifast Elastic Zhermack Spa) was used. (Type IV dental stone (Elite Master; Zermack SpA) was used for pouring the mold. Then according to implant position, angulation, soft tissue height, and inter-occlusal space suitable abutment was selected (Giglio et al. 1999). One of them is angled abutment to correct significant proximity of the implant (Fig. 3).

The screw opening hole of abutment was filled with cork and wax. Acrylic cap on the abutment also are made and then connected to cap of transfer coping with auto-polymerizing acrylic resin (DuraLay Reliance Dental MFG Company) (Fig. 4).

Finally, the connected pieces were under impression with a closed-tray technique and also the use of monophase additional silicone impression material (Monopren transfer; Kettenbach). Sitting of the implant analogue which has abutment analogue controlledon the impression with rotating of them to the right Etleft. In addition before sitting of those components, the connected caps is set on the final impression. The final cast will be sent to a lab to firing of the porcelain.

\section{DISCUSSION}

The placement of multiple implant requires careful diagnosis and treatment planning. When faced with a significant proximity between them, use of an angled abutment together with a straight abutment is a suitable idea. In the past decade, impression techniques have made significant progress. During the prosthetic phase of implant treatment, there are various treatment options facing clinicians in relation to various impression techniques and available materials for making impression. The passive placement of prosthesis on implant and the correct location of implant placement are very important. The mentioned method in this study, especially for making the final cast in implants that have been inserted improperly, is suitable. In some implant systems such as ANKYLOSE, straight and angled abutments possess snap connection for impression. So, if there is proximity of implants, we can use of them. While, in the mentioned method of this study, the acrylic cap and transfer cap can be splint easily with acrylic resin and become conveniently pick up. Also, inserting the abutment and analogue set into the impression is done easily. On the other hand, the precision of this method of impression must be 


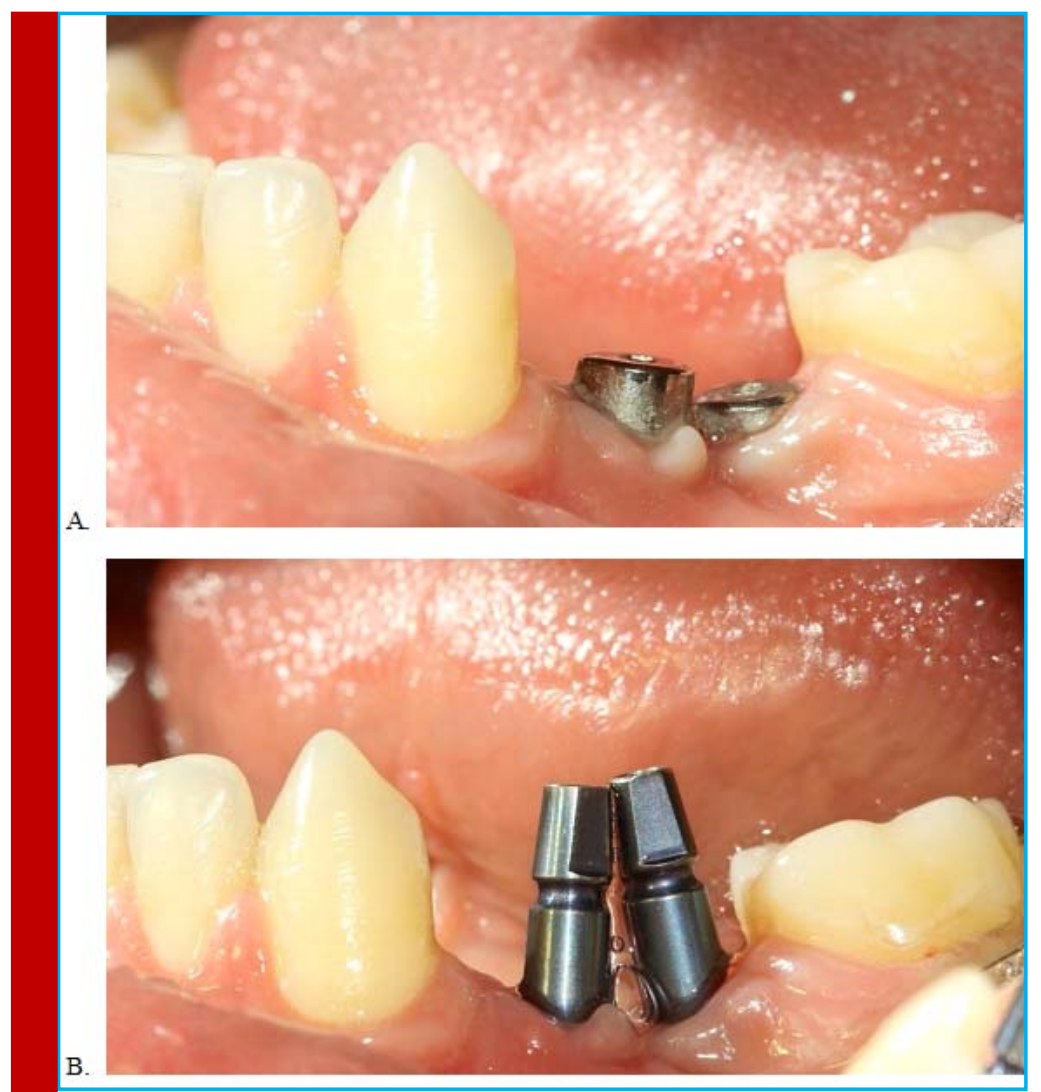

FIGURE 2. A) Intra-oral view of implant fixtures. B) Impression coping to show degree of proximity of implant fixtures.

compared with other techniques when the implants are very close (McCartney et al. 1994; Schneider et al. 2001).

The first advantage of the method in this study is the possibility of impression from a transferable component due to putting the abutments. Second, reducing differences between improper axes of the implants to less than 8 degrees by angled abutments, will increase precision of impression (Lundqvist et al. 1983; Spector et al. 1990). Based on a recent systematic review accuracy of the splint technique compared with non-splint

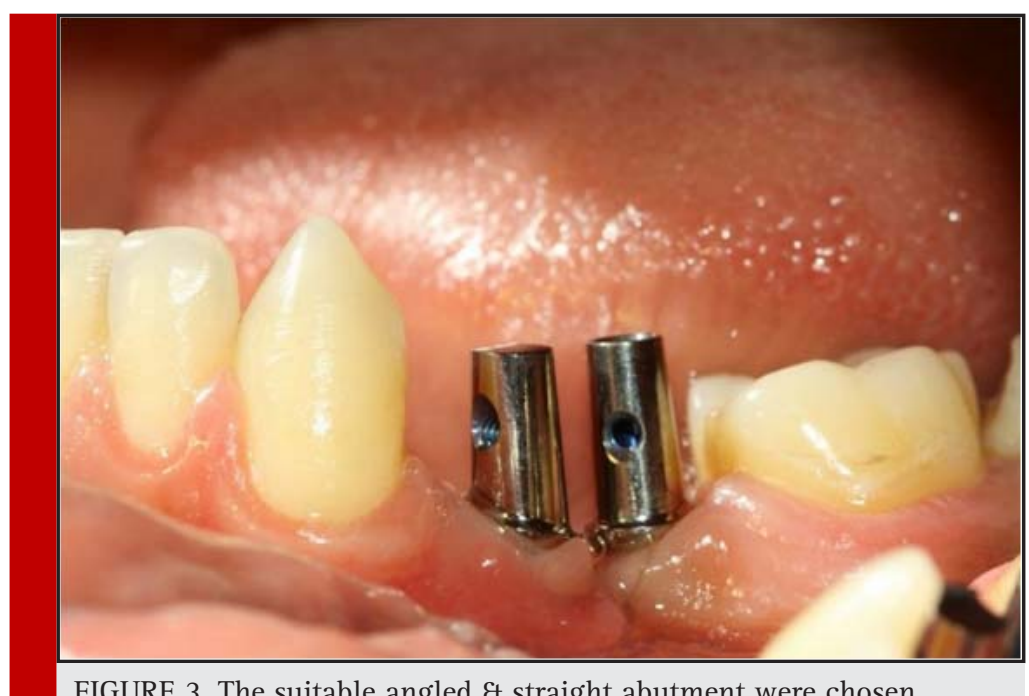

FIGURE 3. The suitable angled \&t straight abutment were chosen. 


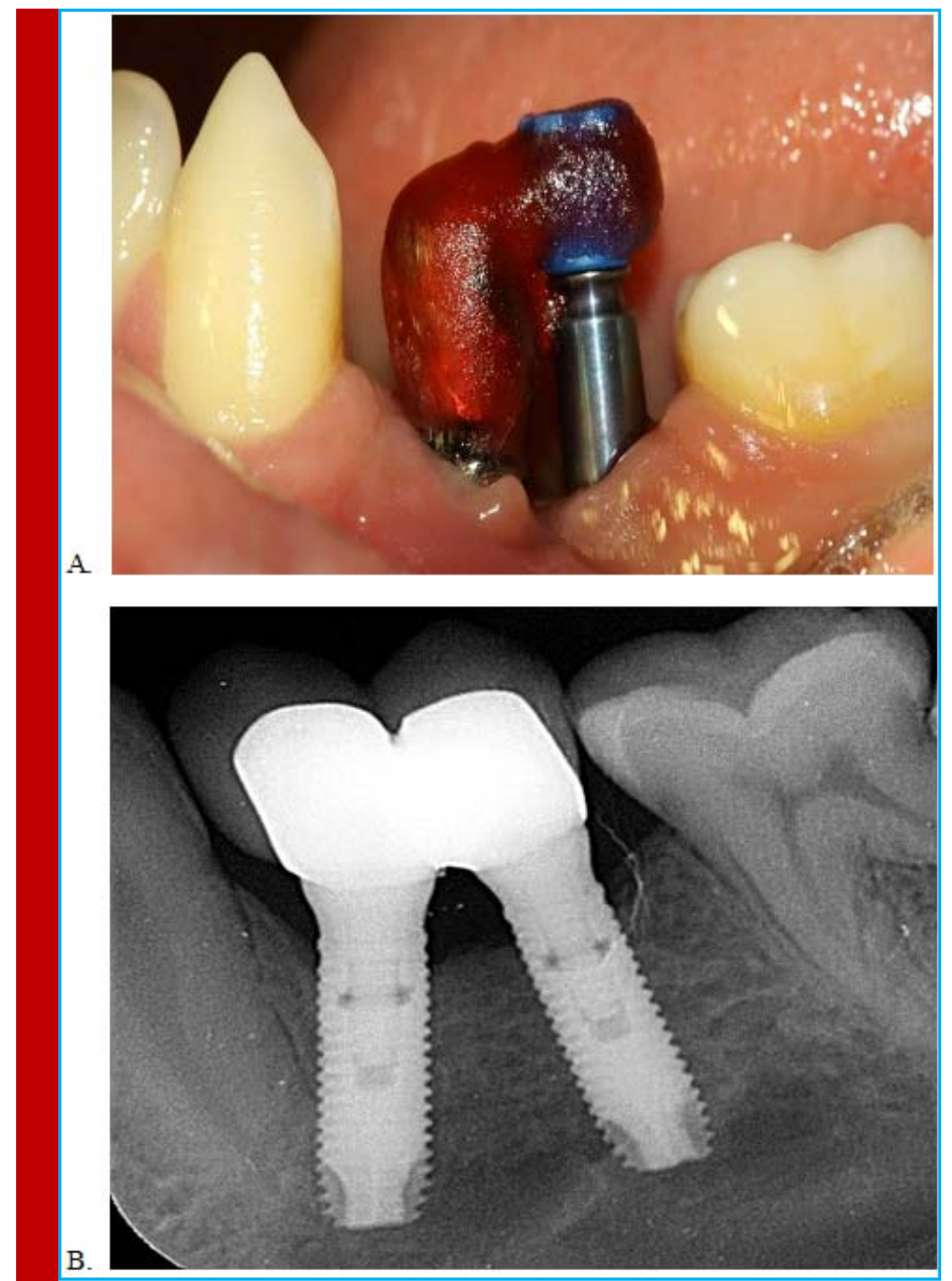

FIGURE 4. A) Abutments with acrylic resin joined to each other. B) The final radiographic view.

is far high. When the number of implants was 3 or less significant differences between the two methods, pick up and transfer, has not been observed. However, for more than 4 implants, the most studies have reported higher accuracy for pick up method (Lee et al. 2008). In addition, the polyether and vinyl poly siloxane (VPS) are recommended as the most widely used impression materials. However, there is no significant difference between these two. Also, there is no consensus about most accurate technique for casting of implants (splint or non-splint and transfer or pick up) (Baig et al. 2014; Papaspyridakos et al. 2015). Little research on other possible factors affecting the implant casting precision is available. Need to be more clinical studies to support the laboratory results.

\section{CONCLUSION}

In this study, a practical method for making the final implant level cast in implants that have been inserted improperly has been proposed. The advantage of the mentioned method in this study is that first putting abutments provide the possibility of casting from a transferable component. Second, increase accuracy of casting by correction of path of improper implants through angled abutment.

\section{REFERENCES}

Assif D., Marshak B., Schmidt A., Accuracy of implant impression techniques. International Journal of Oral \& Maxillofacial Implants, 11, (1996), 216-22. 
Chaimattayompol N., Arbree N.S., Wong S.X., A simple method of making an implant-level impression when presented with limited space, unfavorable implant positions, or problematic implant angulations. The Journal of prosthetic dentistry, 87, (2002), 684-7.

Choi J.H., Lim Y.J., Yim S.H., Kim C.W., Evaluation of the accuracy of implant-level impression techniques for internal-connection implant prostheses in parallel and divergent models. The International journal of oral \&t maxillofacial implants, 22, (2007), 761-8.

Giglio G.D., Abutment selection in implant-supported fixed prosthodontics. International Journal of Periodontics \&t Restorative Dentistry, 19, (1999), 233-41.

Gualini F., Berglundh T., Immunohistochemical characteristics of inflammatory lesions at implants. Journal of clinical periodontology, 30, (2003), 14-8.

Kupeyan H.K., Lang B.R., The role of the implant impression in abutment selection: a technical note. International Journal of Oral \&t Maxillofacial Implants, 10, (1995), 429-33.

Lee H., So J.S., Hochstedler J., Ercoli C., The accuracy of implant impressions: a systematic review. The Journal of prosthetic dentistry, 100, (2008), 285-91.

Lin C.L., Wang J.C., Ramp L.C., Liu P.R., Biomechanical response of implant systems placed in the maxillary posterior region under various conditions of angulation, bone density, and loading. International Journal of Oral \& Maxillofacial Implants, 23, (2008), 57-64.
Lundqvist S., Carlsson G.E., Maxillary fixed prostheses on osseointegrated dental implants. The Journal of prosthetic dentistry, 50, (1983), 262-70.

McCartney J.W., Pearson R., Segmental framework matrix: master cast verification, corrected cast guide, and analog transfer template for implant-supported prostheses. The Journal of prosthetic dentistry, 71, (1994), 197-200.

Schneider A., Kurtzman G., Silverstein L., Improving implant framework passive fit and accuracy through the use of verification stents and casts. Journal of dental technology: the peerreviewed publication of the National Association of Dental Laboratories, 18, (2001), 23-5.

Selecman A.M., Wicks R.A., Making an implant-level impression using solid plastic, press-fit, closed-tray impression copings: A clinical report. The Journal of prosthetic dentistry, 101, (2009), 158-9.

Spector M.R., Donovan T.E., Nicholls J.I., An evaluation of impression techniques for osseointegrated implants. The Journal of prosthetic dentistry, 63, (1990), 444-7.

M.R. Baig, Accuracy of impressions of multiple implants in the edentulous arch: A systematic review. The International journal of oral \&t maxillofacial implants, 29, (2014), 869-80.

P. Papaspyridakos, H. Hirayama, C.J. Chen, C.H. Ho, V. Chronopoulos, H.P. Weber, Full-arch implant fixed prostheses: a comparative study on the effect of connection type and impression technique on accuracy of fit. Clinical oral implants Research, 27, (2015), 1099-105. 